\title{
EM BUSCA DE CURITIBA PERDIDA: RESISTÊNCIA E MEMÓRIA NO INVENTÁRIO DE DALTON TREVISAN
}

Em busca de Curitiba perdida: resistence and memory in Dalton Trevisan's ingenuity

\section{Roberto Nicolatto*}

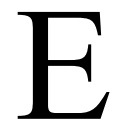

m um dos capítulos de As cidades invisiveis, ${ }^{1}$ Italo Calvino nos faz crer que a memória da cidade está diretamente relacionada ao acontecimento humano, nas simples marcas deixadas em "cada segmento riscado por arranhões, serradelas, entalhes, esfoladuras", ${ }^{2}$ ou na dimensão simbólica que à memória se confere, no tempo passado que se presentifica.

Assim, o viajante veneziano Marco Polo em seu colóquio com Kublai Khan descreve em As cidades invisiveis - no terceiro capítulo dedicado à memória - que a cidade de Zaíra, em que pese seus altos bastiões, nos importa menos pela sua arquitetura imponente que pelas relações humanas que a permeiam.

Inutilmente, magnânimo Kublai, tentarei descrever a cidade de Zaíra dos altos bastiões. Poderia falar de quantos degraus são feitas as ruas em forma de escada, da circunferência dos arcos dos pórticos (...). A cidade não é feita disso, mas das relações entre as medidas do seu espaço e os acontecimentos do passado... ${ }^{3}$

\footnotetext{
* Universidade Tuiuti do Paraná e Universidade do Brasil

1 CALVINO, Italo. As cidades invisiveis. Rio de Janeiro: Companhia das Letras, 1990.

2 Ibid., p. 15.

3 Ibid., p. 14.
} 
Assim, a cidade tem sua escrita demarcada a cada acontecimento, no decorrer da história, que tanto pode permanecer oculto ou ser revelado como num palimpsesto. É como se as sucessivas e antigas transformações se tornassem aparentes e eternas, mediante um processo de raspagem do texto onde está impressa a nova escrita da cidade. E à medida que se avança pelos subterrâneos desta escrita/memória, nos damos conta dos novos significados que emergem de outras leituras e de suas relações culturais e simbólicas.

Neste contexto, a memória assume grande relevância nas narrativas de Dalton Trevisan: “(...) a memória é redundante: repete os símbolos para que a cidade comece a existir", ${ }_{4}^{4}$ nos ensina Italo Calvino, para citar novamente outra passagem de $A s$ cidadesinvisíveis.

A temática da cidade aparece na obra de $\mathrm{DT}^{5}$ desde os tempos da revista Joaquim, editada pelo escritor na década de 40, ou seja, muito antes da publicação de seu primeiro livro, por uma editora comercial, Novelas nada exemplares, que surgiu em 1959.

Em Dalton Trevisan, o espaço da cidade tanto pode estar presente, mesmo que de forma velada, nos contos de costumes-para utilizar a definição proposta por Antonio Hohlfeldt no livro Conto brasileiro contemporâneo, ${ }^{6}$-, como demarcado e inventariado na viagem em que o narrador faz no texto "minha cidade", uma espécie de crônica poética sobre Curitiba publicada pela primeira vez na Revista Joaquim, ${ }^{7}$ de número 6, em 1945.

O texto "minha cidade", posteriormente denominado "Em busca de Curitiba perdida" - o qual abre o livro homônimo, de 1992 - resume a intenção do narrador de demarcar seus espaços preferidos, revelar estruturas sociais e simbólicas inscritas num inventário pessoal, em que tem prevalência o juízo de valor, sob a forma da antítese do sim e do não, da Curitiba que se afirma e se nega.

Desta forma, pode-se encontrar estas marcas em toda a construção do texto, a exemplo dos dois trechos abaixo, pertencentes a "Em busca de Curitiba perdida":

4 Ibid., p. 23.

5 Em alguns momentos, a abreviatura DT será utilizada ao longo do texto em substituição a Dalton Trevisan.

6 HOHLFELDT, Antonio Carlos. Conto brasileiro contemporâneo. 2. ed. rev. e atual. Porto Alegre: Mercado, 1988.

7 Joaquim, n. 6, nov. 1945, edição fac-similar. Curitiba: Imprensa Oficial do Paraná, 2000. Coleção Brasil Diferente.

8 TREVISAN Dalton. Em busca de Curitiba perdida. Rio de Janeiro: Record, 1992. 
"Viajo Curitiba dos conquistadores de coco e bengalinha na esquina da Escola Normal, do Gigi, que é o maior pidão e nada não ganha (a mãe aflita suplica pelo jornal: Não dê dinheiro ao Gigi) (...)"9

"Não, a do Museu Paranaense com o esqueleto do Pithecanthropus erectus, mas do Templo das Musas, com os versos dourados de Pitágoras(...)". ${ }^{10}$

Se no primeiro texto de "minha cidade", na década de 40, Dalton elege os elementos mais significativos desse inventário e delimita o que poderíamos chamar de sua "geografia pessoal da cidade", na republicação do mesmo em outras obras, ainda que com novos títulos ou formatos, ele vai tentar reafirmar e consolidar o que foi dito no discurso original.

O significado da redundância, do discurso que se repete e a preservação de sintagmas-chave desse inventário, em todos os textos subseqüentes, é vital para que a sua cidade - que devido à passagem do tempo será enquadrada no campo da memória afetiva - continue existindo. Mesmo que esta cidade seja vista sob um outro contexto, ou desenhada a partir de um discurso mais conciso, de um novo significante.

A substituição do título "minha cidade" para "Em busca de Curitiba perdida", na verdade, passa a prevalecer a partir da publicação da obra Desastres do amor, ${ }^{11}$ em 1968. Antes dessa mudança, o texto foi publicado em outras três edições diferentes. ${ }^{12}$

O estudo da professora Rosse Marye Bernardi, Dalton Trevisan: Atrajetória de um escritor que se revê, ${ }^{13}$ apresentado em 83 na Universidade de São Paulo, revela que até aquele momento o texto "minha cidade" tinha sido publicado em oito edições e em seis formatos..$^{14}$

9 Ibid., p. 7.

10 Ibid., p. 9.

11 TREVISAN, Dalton. Desastre do amor. Rio de Janeiro: Civilização Brasileira, 1968. p. 141.

12 O texto-base, com ou sem modificações, foi publicado nas seguintes obras e revistas: Minha Cidade. Revista Guaíra, Curitiba, v. 1, n. 9, p. 66, nov. 1949; Guia histórico de Curitiba. In: Guia Histórico de Curitiba. Curitiba, 1953. p. 3; Viagem ao redor de Curitiba. In: Lamentações de Curitiba. Joaquim, Curitiba, 1961.p. 37.

13 BERNARDI, Rosse Marye. Dalton Trevisan: a trajetória de um escritor que se revê. São Paulo, 1983. Tese (Doutorado) - USP.

14 As edições publicadas após Desastre do amor foram: Em busca de Curitiba perdida. In: $O$ vampiro de Curitiba. 2. ed. rev. aum. Rio de Janeiro: Civilização Brasileira, 1970. p. 273; Em busca de Curitiba perdida. In: Desastres do amor. 3. ed. rev. Rio de Janeiro: Civilização Brasileira, 1974. p. 139; Em busca de Curitiba perdida. In. Mistérios de Curitiba. 4. ed. rev. Rio de Janeiro: Record, 1979. p. 84; Em busca de Curitiba perdida. In: 20 contos menores (Antologia escolar). Rio de Janeiro: Record, 1979. p. 56. 
As alterações no formato de "minha cidade" só não foram constatadas do texto-base da revista Joaquim para o publicado na Revista Guaira ${ }^{15}$ - onde inclusive foi mantido o título original-, e no percurso do texto de Mistérios de Curitiba ${ }^{16}$ para 20 contos menores. ${ }^{17}$

Merece destaque o fato do texto ter sido republicado (já com novos formatos) em pelo menos dois momentos marcantes, na história do Paraná e de Curitiba, sempre com o propósito de marcar posição e afirmar a cidade provinciana, a cidade da memória: em 1953, por ocasião das comemorações do I Centenário de Emancipação do Paraná e, em 1992, durante os preparativos do aniversário dos 300 anos de Curitiba, que aconteceria no ano seguinte.

Em 1953, o texto "minha cidade" passa então a se chamar "Guia histórico de Curitiba", sendo editado numa publicação homônima, bem ao estilo dos "cadernos de cordel". Conforme a pesquisa feita por Rosse Marye, além do novo título, a narrativa "apresenta alterações cujo teor evidencia a intenção de satirizar as comemorações desse acontecimento". ${ }^{18}$

Será no "Guia histórico de Curitiba", que ocorrerá a modificação do sintagma "para turista ver" para "inglês ver", expressão que oferece o sentido de uma cidade que se esconde atrás do convencionalismo e das aparências. Além disso, a expressão "eu canto" será substituída por "eu viajo", que vai servir para instaurar o texto no plano da memória. Se "cantar" estabelece o sentido de algo presente, atual, o termo "viajar" sugere o distanciamento, um deslocamento até a cidade do passado.

Nesse inventário reatualizado, que se traduz numa espécie de memorial do que deve ser lembrado, o autor vai continuar negando o discurso de determinadas instâncias relacionadas com o poder que poderíamos caracterizar como a Curitiba oficial (a dos administradores e elite intelectual) em prol da Curitiba humana, povoada de loucos, rufiões, prostitutas, colonos, normalistas de gravatinha, neopitagóricos, soldados do fogo, entre outros.

Como foi demonstrada, a alteração nos títulos, assim como as substituições e supressões nos textos, não são gratuitas e nos ajudam a compreender a relação do autor com sua própria obra e a forma de inseri-la num outro ponto de vista, numa perspectiva que se pela linha estética caminha para a síntese, pelo lado do significado tem como objetivo marcar uma nova posição, e propor um novo entendimento da cidade.

15 Revista Guaira, Curitiba, v. 1, n. 9, p. 66, nov. 1949.

16 TREVISAN, Dalton. Mistérios de Curitiba. 4. ed. rev. Rio de Janeiro: Record, 1979.

17 TREVISAN, Dalton. 20 contos menores (Antologia escolar). Rio de Janeiro: Record, 1979.

18 BERNARDI, op. cit., p. 41. 
Assim, novas perspectivas de leituras se abrem quando se procura compreender a substituição empregada por DT nas reedições do texto. A primeira delas é a concepção de tempo passado, da cidade que passará a se inscrever num outro universo: o da memória. E será, sobretudo, pelo exercício e a afirmação dessa memória que Trevisan pretende manter viva a sua Curitiba perdida.

Outra perspectiva pode ser buscada na própria grafia de "minha cidade", em letras minúsculas, na qual o autor traz à tona uma primeira definição para a sua Curitiba: uma cidade pequena, marcada pelo espírito provinciano de convivência e das relações sociais, ainda sem a contaminação do progresso, e povoada de "personagens menores", de carne e osso, destituídos de qualquer status social.

Dalton Trevisan não tem qualquer pretensão de cantar a grandeza daqueles que detêm o poder, seja em qualquer instância artística ou da administração pública - seja em qualquer tempo. Pelo contrário. Ele vai optar pela "Curitiba menor", escrita em letras minúsculas, que é a dos "bailes familiares de várzeas", do "Gigi, que é o maior pidão e nada não ganha", "das carrocinhas das polacas de lenço colorido na cabeça", da "sociedade secreta das Tulipas Negras", "das normalistas de gravatinhas" e "das meninas de subúrbio pálidas, pálidas que envelhecem de pé nos balcões".

No entanto, a noção de pertencimento oferecida a partir do título "minha cidade" acabará se perdendo, de maneira mais efetiva, com a passagem para "Em busca de Curitiba perdida", em 1968. A exclusão do pronome possessivo e, por conseqüência, do sujeito do discurso, no caso específico do título, nos sugere que essa ocorrência se dá pelo fato de o narrador não mais se reconhecer na cidade onde mora, que acabou se transformando com o progresso acelerado e os planos urbanísticos.

Essa idéia de não reconhecimento vai aparecer com mais evidência anos depois com a publicação de "Curitiba revisitada", ${ }^{19}$ outro texto que se aproxima da crônica e que compõe o livro Em busca de Curitiba perdida: "não te reconheço Curitiba a mim já não conheço/a mesma não é outro eu sou/nosso caso passional morreu de malamorte(...)". De outra maneira, essa noção de não-pertencimento já havia sido aventada na troca da expressão "eu canto" de "minha cidade" para "eu viajo", de "Guia Histórico de Curitiba", o que pressupõe uma busca do que está longe do alcance dos olhos e da vivência do narrador.

Antes de fazermos uma leitura mais específica do significado que o texto "minha cidade" passa a representar ao se chamar "Em busca de Curitiba perdida" é necessário contextualizá-lo e compreendê-lo à luz de sua origem na década de 40 .

19 TREVISAN. Em busca de Curitiba..., p. 88. 
Não há como dissociá-lo do desejo de uma geração liderada por Dalton Trevisan,e que teve a revista Joaquim como veículo de divulgação de suas idéias-de criar no Paraná um movimento de renovação nas artes e na literatura em contraposição aos ideais reacionários e conservadores do movimento paranista e também simbolista, este capitaneado no Paraná pelo poeta Emiliano Perneta.

Sob este ângulo é que o texto "minha cidade" deve ser analisado: qual seja, a partir de um movimento que pretende romper com o passadismo, instaurar novas idéias, o que vai desencadear numa nova maneira de olhar a cidade. Assim, Dalton vai cantar nos seus contos a cidade das criaturas comuns, quando não humildes, conforme o ensaio "Primeiras considerações sobre o contista Dalton Trevisan", escrito pelo crítico Wilson Martins na revista Joaquim de número 14:

É notável a fascinação que essa pobre fauna exerce sobre o contista: e tudo exclusiva e rigorosamente debaixo de um interesse de análise psicológica, de conhecimento do homem, pois o sr. Dalton Trevisan não é político, ou, pelo menos, não pretende fazer de sua arte um veículo de intenções políticas. ${ }^{20}$

Desta forma, a leitura de "minha cidade" se dá através de dois movimentos: o primeiro, e que é predominante na narrativa, está relacionado diretamente ao ponto de vista artístico e literário de conceber a cidade e a própria arte; o outro, com as republicações do texto em momentos históricos importantes, tem um caráter de resistência contra as inovações de uma cidade que está em rápido processo de crescimento e mudanças.

\section{O signo reconstruído}

No processo de ficcionalização da cidade, o texto original de "minha cidade", publicado na revista Joaquim, será várias vezes refeito, retratando as preocupações obsessivas do autor em cortar sintagmas, subtraindo em cada edição o que torna o texto prolixo e sem ritmo poético. Nessa arte de eliminar o que está na superfície, o

20 MARTINS, Wilson. Primeiras considerações sobre o contista Dalton Trevisan. Joaquim, n. 14, p. 7. Edição fac-similar. 
autor persegue a concisão para povoar a palavra do mais rico e complexo significado, conforme a acepção de Ezra Pound. ${ }^{21}$

Apesar das alterações, o corpus narrativo permanecerá no mesmo tempo verbal (na primeira pessoa do indicativo) do primeiro texto, como se fosse uma cidade do presente. Além disso, apesar das sucessivas modificações feitas no texto original de "minha cidade", Dalton irá manter a essência do discurso, preservando os principais espaços físicos, sociais e literários em que o narrador "viaja” ou não, conforme pretendemos demonstrar mais adiante.

Com o lançamento da coletâneaEm busca de Curitiba perdida peloescritor, em 1992, o texto teve o nono formato. O livro foi lançado um ano antes das comemorações dos 300 anos de Curitiba, reunindo 23 textos de diferentes formatos e gêneros (contos e textos tidos como híbridos), retirados de livros do autor, já publicados, ou de sua então recente produção que buscou oferecer novas leituras a respeito da cidade.

Em 1992, a crônica poética "minha cidade" é novamente publicada, trazendo o título "Em busca de Curitiba perdida", que havia sido alterado em 1968. Este texto híbrido ${ }^{22}$ abre o livro e, mesmo sendo antigo e refeito, por si só já instaura um novo discurso, uma voz dissonante ao que irá prevalecer durante os preparativos para as comemorações do aniversário da cidade. Ao publicar novamente o texto, que já se instaura no plano da memória, o autor mais uma vez estará reafirmando, como já foi dito anteriormente, o seu inventário da cidade através da ficção.

É importante notar que na medida em que reafirma seu modelo ideal de cidade e que esta cidade, por conta das sucessivas (e por que não desmedidas) transformações na paisagem urbana, acabou-se tornando uma imagem do passado, Dalton Trevisan vai se opor ao discurso oficial que irá predominar durante o aniversário de cidade. ${ }^{23}$

21 Ezra POUND, em $A B C$ da Literatura. 5. ed. São Paulo: Cultrix, 1990, p. 32, diz que literatura é linguagem carregada de significado. "Grande literatura é simplesmente linguagem carregada de significado até o máximo grau possível”.

22 No ensaio "Pessoa precursor de Dalton: a cidade revisitada", que consta no livro O imaginário da cidade (organizado por Rogério Lima e Ronaldo Costa Fernandes), Ana Maria Filizola observa que os textos híbridos “(...)não contam necessariamente uma história, interferem no real duma forma que se aproxima da crônica; neles se encontram expressões, imagens, vocabulário que freqüentam os textos ficcionais, de tal modo que ficam contaminados por esses elementos e não podem ser lidos senão como ficção (e o que seriam?...)."

23 Isto não significa que DT, em sua obra, acabe por negar os pressupostos básicos da modernidade, porque a exemplo de Charles Baudelaire vai construir sua ficção a partir de fisionomias, de personagens que compõem um cortejo alegórico que circulam pelo universo de uma cidade que, a exemplo de Paris, está em processo de transformação. 
Ao mesmo tempo, vai consubstanciar o poder da memória afetiva e de sensações como um ato de resistência e de denúncia diante do esfacelamento do espaço e das identidades. Conforme diz Walter Benjamin, em seu ensaio "Infância em Berlim" (1933), ${ }^{24}$ o homem urbano é um indivíduo empobrecido em sua experiência vital, por ser incapaz de estocar memórias, já que tudo é transitório.

Na verdade, Walter Benjamim vai utilizar no projeto $A$ obra das passagens (Das Passagens Werk) $)^{25}$ o termo "imagem dialética" como categoria central para decifrar a "mitologia da modernidade", na Paris do século XIX, conforme explica Willi Bolle, em Fisiognomia da Metrópole Moderna. ${ }^{26}$

O método das "imagens dialéticas" proposto na historiografia levada a termo por Benjamin consiste, de acordo com Bolle, em pensar na construção de uma analogia entre o despertar e o recordar. Bolle vai dispor de uma citação do próprio Benjamin para esclarecer essa definição: "Os 'fatos' históricos tornam-se algo que acaba de nos acontecer: fixá-los é uma questão de recordação (Erinnerung). Eo despertar é o caso exemplar do recordar". ${ }^{27}$

Neste raciocínio, a figura do historiador em Benjamim se instaura como aquele capaz de interpretar os sonhos coletivos. Porém, Benjamim, ainda segundo Bolle, vai se encaixar na categoria do historiador materialista que tanto se distancia do conceito de inconsciente coletivo, formulado por Carl Jung, como do significado dos sonhos na produção surrealista:

Enquanto os surrealistas escolhem a forma do 'sonho' para expressar a mitologia da época, o historiador materialista procura elaborar uma forma de "despertar", como método para traduzir a linguagem inconsciente para o conhecimento consciente. $\mathrm{O}$ saber é obtido através de uma operação dialética: do ainda nãoconsciente à consciência despertada, e vice-versa. ${ }^{28}$

24 BENJAMIN, Walter. Obras escolhidas II: rua de mão única. 5. ed. São Paulo: Brasiliense, 1995.

25 Das passagens werk, ed. Rolf Tiedemann, 1982, GS, v. 1 e 2. Benjamin, na verdade, não chegou a dar um título definitivo a esse projeto amplo e inacabado, no qual trabalhou entre 1927 a 1940, ano de sua morte. O título da obra Das passagens foi dado por Tiedemann em 1982.

26 BOLLE, Willi. Fisiognomia da metrópole moderna: representação da história em Walter Benjamin. 2. ed. São Paulo: Editora da Universidade de São Paulo, 2000. p. 61.

27 Ibid., p. 63.

28 Ibid., p. 62. 
A história como objeto de construção e não como algo morto e solidificado como quer as instâncias do poder - e que leva a engendrar o conceito de indivíduo apenas como espectador e não mais como sujeito -, nos permite aproximar o projeto de Dalton com a publicação de "Em busca de Curitiba perdida", em 1992, à figura do historiador materialista, de Benjamin. Isto porque, a cidade de DT se traduz num sonho do passado, mas que se presentifica em seu processo dialético.

Nesta busca de reinvenção dos acontecimentos (que se traduz numa espécie de happening), não se deve perder de vista que a cidade da memória será sempre uma cidade labiríntica. E, nesta perspectiva, Dalton vai percorrer as trilhas do passado, escavar o subterrâneo e recontar a história numa perspectiva até então desprezada pela literatura e pelas instituições culturais da cidade.

A Curitiba que o narrador viaja é a capital paranaense dos anos 40 e 50, quando a população não passava de 350 mil habitantes, época em que era comum o footing na rua XV de Novembro e nos cinemas. "Para as pessoas que viveram os anos 50 em Curitiba, não seria difícil perceber o quanto e como a cidade foi transformada", diz Antônio Cesar de Almeida Santos, em Memórias e Cidade..$^{29} \mathrm{Da}$ década de 60 para cá, Curitiba se transformou, perdeu a medida da província e nela o narrador não se vê, não mais se identifica.

No texto de "minha cidade" e, posteriormente, "Em busca de Curitiba Perdida", o escritor estará anunciando alguns dos espaços que servirão de cenário para o enredo de seus pequenos dramas provincianos. Os espaços de domínio público predominam e vão funcionar como pontos de encontro dos personagens, fora do universo do lar, como o Buraco do Tatu, a Ponte Preta e a Zona da Estação. Além disso, DT vai apresentar alguns personagens, entre eles Gigi, um garoto com problemas psicológicos que protagoniza um dos contos do autor, já em Novelas nada exemplares. ${ }^{30}$

A cidade descrita pelo narrador em primeira pessoa (não confundir com o autor empírico, na acepção de Umberto Eco) define uma escolha, um juízo em relação àquilo que se pretende afirmar ou negar no âmbito da província dos anos 40, 50 .

O narrador deixará explícito nessa "crônica poética" o seu posicionamento estético, político (não na acepção partidária) e cultural, através de uma linguagem marcada pela repetição e pelo método antitético, em que se opõem os termos "eu viajo" e "não viajo", num processo de busca incessante para reconstruir na memória a cidade.

29 SANTOS, Antônio Cesar de Almeida. Memórias e cidade. Depoimentos e transformação urbana em Curitiba (1930-1990). 2. ed. Curitiba: Aos Quatro Ventos, 1999.

30 TREVISAN, Dalton. Novelas nada exemplares. 6. ed. rev. Rio de Janeiro: Record, 1994. 
Em Dalton Trevisan, a escavação de significados para reatualizar a cidade, a partir da memória, assume caráter de resistência. Se nos contos tem supremacia o discurso em terceira pessoa, numa temática a revelar a miserabilidade das relações, a incomunicabilidade e o caminho da degradação dos personagens, nos outros textos tidos como híbridos também prevalece a ironia, a reflexão sobre aspectos do cotidiano dos moradores de uma cidade que não mais existe.

Neste sentido, o narrador no primeiro exemplo é mais ficcional e, por conseqüência, mostra-se bem próximo do processo discursivo, enquanto no segundo caso pode-se dizer que ele se aproxima da vertente memorialista e da figura de um cronista. É esse distanciamento da situação ficcional que permitirá um caráter opinativo nos textos considerados híbridos.

Reafirmar os espaços, em sua maioria não mais existentes, mas que podem ser identificados na memória de antigos moradores de Curitiba, seguindo suas mais distraídas e sinuosas marcas, pegadas, é compreender como no mito do navio de Argos que a cidade não pode desprezar a sua história.

Além disso, o que torna o texto "Em busca de Curitiba Perdida" bastante revelador ao ser republicado nas proximidades dos festejos dos 300 anos não será a visão saudosista e romântica da cidade nas décadas de 40 e 50 . Na verdade, o que está em jogo neste caso é uma questão ideológica e intelectual, qual seja, a divisão que o autor estabelece entre duas instâncias - a dos espaços marginais e das pessoas comuns e os espaços ditos “oficiais", relacionados ao poder seja ele político (não no sentido partidário) ou cultural - e a sua preferência pela primeira.

Esta compreensão, no entanto, se torna mais completa quando se tem a leitura de todos os textos híbridos que compõem o livro lançado em 1992, sobretudo a narrativa "Curitiba revisitada", onde há críticas à Curitiba "enjoadinha" e "para inglês ver" dos anos 90 .

Esta perspectiva ideológica vai percorrer todas as narrativas de Dalton Trevisan, consideradas "híbridas", o que o torna coerente em seu discurso, revelando que, independente de quem e de que agremiação partidária esteja no poder, ele estará sempre condenando a constante transformação urbana da sua cidade e os efeitos perversos do progresso a qualquer custo.

Vale a pena traçar uma comparação entre o texto de "Em busca de Curitiba perdida”, publicado em 1992 e o original "minha cidade", editado pela primeira vezna revista Joaquim, na década de 40, para entendermos as transformações sofridas pelo texto - em que pese as necessárias adequações de natureza estética -, e sua correspondência com as percepções do autor em relação à vida urbana,

Do primeiro para o segundo, nota-se a supressão de vários sintagmas, que traduziam com mais amplitude o modus vivendis da província, e que em sua maioria 
estão diretamente relacionados àqueles em que o autor diz que "viaja". Abaixo, relaciono alguns deles, os quais estavam em "minha cidade" ${ }^{31}$ e desapareceram na versão "Em busca de Curitiba perdida":

...dos cães vagabundos que passeiam impunes pela rua principal e ali se amam zombando da gaiolinha da prefeitura... ...dos bas-fond do 111, do Pombal, do Petit Polais, esses nomes convidativos que escondem um submundo de fêmeas em vestidos de baile...

Curitiba do registro policial do "Diário da Tarde", onde só onde as donzelas em gesto tresloucado ingerem formicidas por causa de amores, os maridos dão surras épicas em mulheres prevaricadoras, viúvos que se enforcam de saudades nas bandeirolas do banheiro...

Curitiba de um ou dois sujeitos com ataques epilépticos nas ruas, - das cargas da Guarda Cívica, a cavalo e sabre desembainhado, nas noites vermelhas de agitação popular - dos comícios do PCB na praça, qual cópia cinematográfica da Revolução Francesa, esta Curitiba eu canto.

Após as constantes supressões, restaram como cenários/espaços dos acontecimentos da cidade e nos quais o autor "viaja" a Zona da Estação e seus prostíbulos, as ruas de lama da periferia, as filas de ônibus às seis da tarde, o relógio da Praça Osório, o bebedouro do Largo da Ordem, as pensões de estudantes, o Templo das Musas (Instituto Neopitagórico), a Ponte Preta da Estação, os conquistadores na esquina da Escola Normal, a Sociedade Operária Internacional Beneficente O 14 De Janeiro, a Curitiba das conferências dos 12 positivistas e o Buraco do Tatu.

Ao que tudo indica, em que pese a menor quantidade de informações ao leitor sobre o universo de personagens e espaços do imaginário daltoniano, as supressões em relação à "minha cidade" se prestam tão somente às intenções do autor de tornar o texto mais sucinto, seguindo uma tendência que predomina na configuração e reatualização de suas narrativas. 
Da mesma forma, também não vão se configurar qualquer alteração na carga semântica o aparecimento no texto de "Em busca de Curitiba perdida" de outros espaços como a Curitiba "dos Chás de Engenharia, onde as donzelas aprendem de tudo, menos a tomar chá", ${ }^{32}$ a "Curitiba em passinho floreado de tango que gira nos braços do grande Ney Traple" ${ }^{33}$ e a "Curitiba da briosa bandinha do Tiro Rio Branco que desfila aos domingos na Rua 15 ". ${ }^{34}$

De outro modo, o autor fez prevalecer, com raras modificações, os mesmos sintagmas reveladores de seu juízo a respeito da cidade em que ele "não viaja". E assim, continua "não viajando" na Curitiba da "Academia Paranaense de Letras, com seus 300 milhões de imortais" ${ }^{35}$ e do Museu Paranaense, que no primeiro formato vem precedido da expressão "onde nenhum curitibano já entrou"36 e na última "com o esqueleto do Pithecanthropus erectus". ${ }^{37}$

A única supressão foi do seguinte sintagma que também se relaciona com a cidade que ele não canta: "Curitiba, não a das Lojas Americanas, Sloper e confeitaria Guaraicá, que os turistas visitam para depois contar que conhecem a cidade(...)". ${ }^{38}$

Na última versão de "Em busca de Curitiba perdida", o narrador também vai reafirmar seu posicionamento contrário à Curitiba simbolista do céu azul, de Alberto de Oliveira, e da cidade de Emiliano Perneta, "onde o pinheiro é uma taça de luz". Essa expressão irônica, na verdade, é uma paráfrase de um verso do poema "Sol", do autor paranaense: "O pinheiro - Eu sou como uma taça erguida para a luz...".

Reproduzo abaixo (nos dois parágrafos seguintes) o texto das duas versões para mostrar que além da substituição de "eu não sei cantar" ${ }^{39}$ para "não viajo", ${ }^{40}$ alguns nomes foram modificados ou retirados na comparação entre os dois textos.

Na versão de "minha cidade", o sintagma foi publicado da seguinte forma:

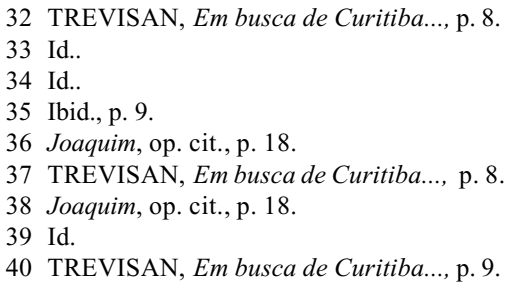


Eu não sei cantar Curitiba, a de Emiliano Perneta, onde o pinheiro é uma taça de luz; de Alberto de Oliveira, onde oh! O céu é azul; de Martins Fontes, que é a cidade sorriso, ou de Moacyr de Las Palmas Chaves, com suas flores, músicas e cristais. Essa Curitiba não é a minha, que eu canto.

Já o texto de "Em busca de Curitiba perdida" diz o seguinte:

Não viajo todas as Curitibas, a de Emiliano, onde o pinheiro é uma taça de luz; de Alberto de Oliveira do céu azulíssimo; a de Romário Martins em que o índio caraíba puro bate a matraca, barquilhas duas por um tostão; essa Curitiba merdosa não é a que viajo.

Ou seja, o narrador continua ironizando a visão poética e o discurso positivo a respeito da cidade. Quanto à referência a Romário Martins, a professora Rosse Marye diz que a citação provavelmente remete ao conhecido texto do historiador de Estudos sobre o indígena,

criticando o diletantismo de seu autor, destituído de qualquer formação científica, mas cultuado oficialmente. Daí a ironia da imagem do índio caraíba puro a bater matraca oferecendo barquilhas, o adjetivo puro em evidente contraste com a ação indicada, sugerindo a ausência de critério científico na avaliação dos fatos e da história. ${ }^{41}$

Neste sentido, Dalton preserva no texto "Em busca de Curitiba perdida" sua posição contrária à retórica paranista, insurgindo-se contra a imagem idealizada de Curitiba, representada pela busca da estética do belo previsível, de um cântico exaltador do espaço por demais iluminado, de um "céu azulíssimo", como diria Alberto de Oliveira.

41 BERNARDI, op. cit., p. 67. 
As críticas do autor à estética simbolista de Emiliano Perneta não ficarão restritas a "Em busca de Curitiba perdida", mas também a outro texto intitulado "Emiliano, poeta medíocre", ${ }^{2}$ publicado na edição de número 2 da revista Joaquim, de 1946, e presente também no livro Em busca de Curitiba perdida, em que classifica de "medíocre" o príncipe dos poetas e fundador da Academia Paranaense de Letras.

Dalton abre seu artigo na revista Joaquim abordando a mística que a cidade criou em torno da figura de Emiliano Perneta que, segundo ele, foi uma vítima da província em vida e morte. Diz ele na seqüência: "Em vida, a província não permitiu que ele fosse o grande poeta que podia ser, e, na morte, o cultua como sendo o poeta que não foi". Num trecho mais adiante, afirma: "E a província cingiu-lhe a fonte com uma coroa de louros, a fim de ele julgar-se, em sua vaidade e no seu orgulho, o eleito dos deuses; esta é a culpa da província, esta é a culpa de Emiliano também".

Trevisan não vai condenar Emiliano apenas pela sua frustrada experiência literária e por fazer "uma poesia de casinha de chocolate", "de valores cômodos", "imagens surradas de dicionário greco-latino" e de transportar para a nossa língua uma cópia mal feita do simbolismo francês. Ele também vai criticar o anacronismo da obra do príncipe dos poetas, desligada da vida e de seu tempo.

Na verdade, a questão proposta por Dalton Trevisan ultrapassa o âmbito da crítica específica. Ela precisa ser entendida num contexto mais amplo, afinal de contas ele pertencia à geração do pós-guerra em que abordar a inquietude e o sofrimento humano era mais significativo que cantar o pinheiro como taça de luz.

Ademais, a revistaJoaquim nascia com a idéia não só de homenagear todos os joaquins do Brasil (intenção que está explicitada no primeiro número da revista) como também propor uma arte de caráter cosmopolita e inovadora em contraposição à estética provinciana do simbolismo-que até a década de 40 reinou absoluta no Paraná - e da qual Emiliano era seu principal representante.

Havia também a convicção entre os novos artistas de que a posição hegemônica ocupada pelos simbolistas e pelo dito movimento paranista de certa maneira contribuíra para sufocar o surgimento de um ideário mais crítico; e um exemplo teria sido o fato de o movimento modernista ter passado em "brancas nuvens" no Paraná.

Retornando à análise das transformações sofridas pelo texto "minha cidade", vale ressaltar que ao republicá-lo durante as comemorações dos 300 anos de aniversário de Curitiba, Dalton vai não só atualizar como ampliar sobremaneira o 
seu significado, através de uma sobreposição. Isto porque no formato de "Em busca de Curitiba perdida", ele vai preservar de algum modo a essência do discurso do texto original ao mesmo tempo em que irá enquadrá-lo no plano da memória.

Este significado por si só ganha corpo na própria escolha de Em busca de Curitiba perdida como título da coletânea, lançada naquela ocasião, e também pela incorporação de textos mais atualizados como "Curitiba revisitada" que se reveste de uma crítica mordaz contra as transformações ocorridas, mais recentemente, na estrutura da cidade.

E será após concluir a sua viagem de reconhecimento ou cantar as suas preferências catalogadas, tanto em "minha cidade" quanto no texto "Em busca de Curitiba perdida", que o narrador vai enfim conceituar a cidade, revestir-lhe do que considera sua mais plena significação: Província, Cárcere e Lar. Essa denominação, por sua vez, abre uma nova perspectiva de leitura muito mais cabível nos contos do autor do que nos textos considerados híbridos.

\section{RESUMO}

Este estudo tem como objeto de análise a "crônica poética" "minha cidade", do escritor paranaense Dalton Trevisan, e as modificações pelas quais passou ao ser republicada com novos títulos e formatos em 1953, por ocasião do I Centenário de Emancipação do Paraná, e em 1992 durante os preparativos de aniversário dos 300 anos de Curitiba, comemorado no ano seguinte.

A intenção é demonstrar de que maneira o texto "minha cidade" passa a se configurar a partir de sua publicação sob novos formatos e com outros títulos primeiramente "Guia histórico de Curitiba" e depois "Em busca de Curitiba perdida"e o que estará representando num contexto de duas datas comemorativas, ou seja, como um contraponto à prevalência do discurso do establishment.

A cada republicação desta "crônica poética", que identifica os espaços e os personagens em que o narrador "viaja", Dalton busca instaurar a sua cidade no universo da memória e do que é permanente. E mais do que isso: reafirma um inventário pessoal a revelar preferências estéticas e posições bem marcadas quanto às transformações urbanas vivenciadas por Curitiba.

Palavras-chave: Dalton Trevisan, literatura e cidade, "Em busca de Curitiba perdida". 


\begin{abstract}
The objective of this study is to analyze the "poetical chronicle" entitled "minha cidade" by Dalton Trevisan, a writer from PR, and the changes it suffered when it was republished under new titles and formats in 1953, during the I Centenary of the Emancipation of Paraná and in 1992, during the preparations for the $300^{\text {th }}$ anniversary of Curitiba, and commemorated in the following year of 1993.

The intention is to demonstrate the way the text of "minha cidade", after the publication under new titles - "Guia histórico de Curitiba", first, and "Em Busca de Curitiba perdida", afterwards - and their new formats, starts to suffer a process reshaping, and what influence both of the commemorative dates will represent to the results, in other words, as a response to the prevalence the discourse of the establishment imposes.

In each republication of this "poetical chronicle", which describes the ambience and the characters the narrator "navigates" through, Dalton tries to set his city in the universe of memory and of what is permanent. And most especially, it reaffirms a revealing personal inventory of aesthetic preferences and well-defined opinions in relation to the urban transformations that occurred in Curitiba.

Key-words: Dalton Trevisan, Literature and city, "Em busca de Curitiba perdida".
\end{abstract}

\title{
REFERÊNCIAS
}

BENJAMIN, Walter. Obras escolhidas III: Rua de mão única. 5. ed. São Paulo: Brasiliense, 1995. Das passagen-werk. Rolf Tiedemann. (Ed.). 1982, GS. 2 v.

BERNARDI, Rosse Marye. Dalton Trevisan: a trajetória de um escritor que se revê. São Paulo, 1983. Tese (Doutorado) - Universidade de Sâo Paulo.

BOLLE, Willi. Fisionomia da metrópole moderna. Representação da história em Walter Benjamin. 2. ed. São Paulo: USP, 2000.

CALVINO, Ítalo. As cidades invisíveis. São Paulo: Companhia das Letras, 1990.

EMILIANO, poeta medíocre. Joaquim, Curitiba, n. 2, p. 16-17, jun. 1946. Edição fac-similar.

FILIZOLA, Anamaria. Pessoa precursor de Dalton: a cidade revisitada. In: LIMA, Rogério; FERNANDES, Ronaldo Costa. O imaginário da cidade. Brasília: Unb, 2000.

GUIA HISTÓRICO DE CURITIBA. Curitiba, 1953. p. 3.

HOHLFELDT, Antônio. Conto brasileiro contemporâneo. Porto Alegre: Mercado Aberto, 1988.

MARTINS, Wilson. Primeiras considerações sobre o contista Dalton Trevisan. Joaquim, Curitiba, n. 14, p. 7, out. 1947. Edição fac-similar. 
POUND, Ezra. ABC da literatura. 5. ed. São Paulo: Cultrix, 1986-1990.

REVISTA GUAÍRA, Curitiba, v. 1, n. 9, p. 66, nov. 1949.

SANTOS, Antônio Cesar de Almeida.Memórias da cidade: depoimentos e transformação urbana em Curitiba (1930-1990). 2. ed. Curitiba: Aos Quatro Ventos, 1999.

TREVISAN, Dalton. Minha cidade.Joaquim, Curitiba, n. 6, p. 18, nov. 1946. Edição fac-similar.

___. Em busca de Curitiba perdida. Rio de Janeiro: Record, 1992.

. Desastres de amor. Rio de Janeiro: Record, 1979.

. Mistérios de Curitiba. 5. ed. Rio de Janeiro: Record, 1996.

. Novelas nada exemplares. 6. ed. rev. Rio de Janeiro: Record, 1979.

20 contos menores (antologia escolar). Rio de Janeiro: Record, 1979. 